\title{
Arbitraje, Conciliación y Mediación en el seno del Consejo Superior de Cooperativas de Euskadi ${ }^{1}$ *
}

\author{
Santiago Merino Hernández \\ Letrado Asesor del Consejo Superior de Cooperativas de Euskadi
}

\section{A) Los antecedentes del arbitraje cooperativo en el País Vasco}

El Estatuto de Autonomía de la Comunidad Autónoma del País Vasco, en el punto 23 del artículo 10, establece la competencia exclusiva en materia de cooperativas, todo ello de conformidad con la legislación general en materia mercantil.

Fruto de esa competencia exclusiva, el legislador vasco elaboró la Ley 1/1982, de 11 de febrero, de Cooperativas, En esta norma, ya derogada (Ley 1/1982), se señalaba en el punto 2.f) de su artículo 70, que entre las funciones que se le asignaban al Consejo Superior de Cooperativas de Euskadi (en adelante CSCE), estaba la de «arbitrar en cuestiones litigiosas que se susciten entre las Cooperativas o entre éstas y sus socios, cuando ambas partes soliciten el arbitraje o estén obligadas a ello a tenor de sus Estatutos».

Pero, aparte de institucionalizar el arbitraje, la citada Ley no reguló nada más, razón ésta por la que algunos autores opinaron en su día que el arbitraje cooperativo vasco nacía huérfano de una deseada regulación procedimental, lo que originó que en el mismo año 1982 comenzaran los intentos de sentar las bases de lo que sería este arbitraje, tendente todo ello a solventar lo que se presentaba como una de las asignaturas pendientes del cooperativismo vasco.

De esta forma los antecedentes concretos de la actual regulación cooperativa los hemos de encontrar en el Anteproyecto de Ley de

1 Conferencia impartida en el III simposio sobre la cultura económica vasca: la resolución de conflictos en las cooperativas. Universidad de Deusto. 28 de octubre de 2004.

* Este artículo no fue incorporado, por error, en el Boletín AIDC anterior. Subsanamos el defecto habido, reiterando las disculpas al autor. 
Arbitraje Cooperativo, reconducido acertadamente hacia la vía del Reglamento propio gracias, entre otros, a la intervención de especializados juristas que aconsejaron desechar el anteproyecto por diversos motivos, entre los cuales estaba el evitar un supuesto recurso de inconstitucionalidad que retrasaría una rápida asunción del servicio arbitral por el CSCE.

Sin embargo, en el momento de la redacción de los diferentes borradores de Anteproyecto que se fueron presentando en el seno del CSCE ya se pusieron las directrices principales que inspirarían las ulteriores regulaciones, y entre las que cabe destacar las siguientes:

a) En lo que a las cuestiones relativas al ámbito competencial se refiere, se regulaba decididamente un arbitraje que atendiera a las discrepancias que se suscitaran entre la cooperativas y sus socios, o entre los socios de la misma en su seno, sin olvidar a las Federaciones de Cooperativas o las asociaciones de las mismas, que también podrían acudir al arbitraje cooperativo.

b) Se separaba claramente las dos fases del arbitraje: una inicial de instrucción del expediente y otra estrictamente arbitral tendente a la emisión del laudo.

c) Ya en aquel entonces se empezó a hablar de la gratuidad del arbitraje, por lo menos por parte de algunos de los ponentes. Se definía un arbitraje como servicio público de atención a unos sujetos muy concretos como eran, con carácter general, las cooperativas y sus socios.

d) Así mismo, ya se destacaba que el futuro arbitraje cooperativo dependía del prestigio que adquiriera el método arbitral y de hacer evidentes sus ventajas y su razón de ser.

El Anteproyecto de Ley de Arbitraje Cooperativo fue aprobado por el CSCE el 23 de julio de 1986, si bien fue reconducido, como se ha indicado, a la vía de Reglamento propio.

\section{B) El Reglamento de Arbitraje Cooperativo del Consejo Superior de Cooperativas de Euskadi de 9 de febrero de 1989}

El mandato legislativo contenido en el artículo 70 de la Ley 1/1982 se concretó definitivamente mediante la aprobación el 9 de febrero de 1989 del Reglamento de Arbitraje Cooperativo del CSCE que fue publicado en el Boletín Oficial del País Vasco el 11 de mayo igualmente de 1989. 
Sin animo de extendernos en la explicación de una normativa ya derogada sí diremos que además de dar comienzo a la aplicación del arbitraje en las sociedades cooperativas introdujo una serie de aportaciones de las que sin duda el actual Reglamento es heredero.

En todo caso, sí diremos que el nacimiento del arbitraje del CSCE no significó que esta entidad pública sea la única que pueda resolver los conflictos surgidos en las entidades cooperativas de la Comunidad Autónoma del País Vasco. Y a esta conclusión llegamos por entender que no se ha consagrado en norma alguna al CSCE como instancia arbitral exclusiva en la que se deban dirimir todos los conflictos cooperativos. Pero además, no hay nada que impida en nuestro ordenamiento que las partes afectadas en un conflicto cooperativo puedan acudir con igual derecho a otros árbitros cuando lo crean conveniente.

Sin embargo, el CSCE, a diferencia de lo que ocurre con otras asociaciones o corporaciones que desempeñan funciones arbitrales, se encontraba obligado a administrar los arbitrajes a los que se refería el artículo 70, cuando así se lo solicite cualesquiera de las partes en conflicto de conformidad con el artículo 1 del Reglamento por aquel entonces en vigor.

Este artículo 1 delimitaba el objeto del arbitraje cooperativo y los requisitos que debían reunir los asuntos; el artículo 2 determinaba las menciones obligatorias que debía recoger la solicitud de arbitraje que se cursara al CSCE, para establecer en el artículo 3 la forma por la que el CSCE aceptaba o rechazaba el conocimiento del asunto.

Para la tramitación de los arbitrajes el CSCE disponía de una lista de árbitros elaborada en base a las propuestas de las Federaciones de Cooperativas representadas en el propio CSCE y de los llustres Colegios de Abogados de los Tres Territorios Históricos de la Comunidad Autónoma del País Vasco.

El procedimiento que se reguló (artículos 5 a 11) apostó decididamente por la escritura frente a la oralidad, si bien el desarrollo posterior demostró que no se incurrió en los mismos defectos que agobian todavía hoy a los Juzgados y Tribunales. Por otra parte, el Reglamento recogía como propios, no hace falta resaltar que siguiendo el modelo de la Ley de Enjuiciamiento Civil, determinados trámites de amplia tradición como era la exigencia preceptiva de la conciliación, que poca o nula utilidad tuvo; la fase preclusiva de alegaciones iniciales, la tam- 
bién fase preclusiva de prueba, y por último la igualmente preclusiva de conclusiones.

A pesar de las tendencias ya apuntadas relativas a la necesidad de que el arbitraje fuera gratuito, no se optó por esa modalidad y así, el artículo 12, establecía que en el laudo se fijarían las costas del arbitraje que incluirían los honorarios de los árbitros debidamente justificados y los gastos y expensas habidos en el procedimiento.

Por último, hemos de señalar que aunque las solicitudes de arbitrajes que se tramitaron conforme a este Reglamento no fueron muchas, la mayoría de ellas se referían al régimen de liquidación de las aportaciones a capital de los socios en caso de baja, así como sobre el régimen de distribución del resultado dentro de la cooperativa.

\section{C) El Arbitraje Cooperativo en la Ley 4/1993, de 24 de junio, de Cooperativas de Euskadi}

En relación a la Ley 4/1993, de 24 de junio de Cooperativas de Euskadi (en adelante LCE), señalaremos que no se alteró sustancialmente, en lo que al arbitraje cooperativo se refiere, la dicción de la Ley 1/1980, si bien se mejoró técnicamente su redacción. Así, el artículo 145.2.f), también regulando las funciones del CSCE, señala que a esta institución pública le corresponde «Intervenir por vía del arbitraje en las cuestiones litigiosas que se susciten entre las cooperativas, entre éstas y sus socios, o en el seno de las mismas entre sus socios, cuando ambas partes lo soliciten o estén obligadas a ello a tenor de sus Estatutos, Reglamento Interno o por cláusula compromisoria. En todo caso la cuestión litigiosa debe recaer sobre materia de libre disposición por las partes conforme a derecho y afectar primordialmente a la interpretación y aplicación de principios, normas, costumbres y usos de naturaleza cooperativa.

En relación a la nueva redacción que se da al arbitraje cooperativo, vemos que se amplían las cuestiones litigiosas que son susceptibles de ser sometidas al arbitraje del CSCE al introducirse las que se produzcan en el seno de una cooperativa entre los socios de la misma (en este sentido es habitual - y de hecho ya ha tenido ocasión de intervenir el CSCE en varias ocasiones- que se produzcan conflictos por ejemplo entre socios de una cooperativa de viviendas).

Por otro lado, se establece que la intervención del CSCE se realice cuando sea solicitado por ambas partes (algo que no ofrece dudas) 
pero también cuando estén las partes obligadas a ello a tenor no solamente de sus Estatutos sino incluso de su Reglamento de Régimen Interno.

Más interés si cabe puede tener el artículo 145.2.f) en su parte final cuando señala que la cuestión debe recaer sobre materia de libre disposición por las partes conforme a derecho, y afectar primordialmente a la interpretación y aplicación de principios, normas, costumbres y usos de naturaleza cooperativa.

Frente a un criterio restrictivo en cuanto a las posibilidades de conocer cuestiones litigiosas (tan sólo cuando afecten a la interpretación y aplicación de principios, normas, costumbres y usos de naturaleza cooperativa), aparece la posibilidad de conocer litigios que hagan referencia a genéricos aspectos de derecho privado y no sólo «cooperativos». En efecto, si sólo se hubiera pretendido un arbitraje con los condicionantes del artículo citado, la dicción hubiera sido, por ejemplo, «exclusivamente» o «únicamente». Con esto parece entenderse que el legislador permitió tácitamente que el arbitraje del CSCE se extendiese a otras materias que, no siendo de naturaleza cooperativa, harían referencia a aspectos de derecho privado, con el tan sólo límite de la Ley de Arbitraje.

Con todo lo señalado, era evidente que con la aprobación de la LCE se abrían nuevas posibilidades para el arbitraje cooperativo vasco que motivarían la reforma del mismo.

\section{D) La reforma del arbitraje cooperativo vasco en el marco del nuevo derecho de arbitraje}

Al amparo de la nueva regulación y con el objetivo inequívoco por el CSCE de apostar por el desarrollo definitivo del arbitraje cooperativo, se apuntaron una serie de líneas de actuación tendentes a superar la situación existente hasta la fecha. Si bien no podemos obviar el considerable esfuerzo que se había realizado en el CSCE, tenemos que reconocer que muchas veces el arbitraje se consideraba como una "función menor» ante lo que podía significar otra de mucho más calado como es la de promoción y difusión del cooperativismo.

Pues bien, en el marco de la citada revisión, se concluyó que la función de arbitraje, inevitablemente unida a la de la conciliación, debía ocupar lugar prioritario en el devenir futuro de la Institución pública. 
Las tendencias de reforma, siempre buscando la prestación de un servicio público a las cooperativas y sus organizaciones representativas, fueron las siguientes:

a) Reforma del Reglamento de Arbitraje de 1989, fundamentalmente en el desenvolvimiento de los procedimientos, al objeto de incorporar todas las novedades que en ámbitos similares se venían dando, al tiempo que se superarían las lagunas que la práctica había puesto de relieve.

b) Potenciación de la conciliación como, incluso, alternativa (no excluyente) al arbitraje.

c) Aprovechamiento de la «auctoritas» del CSCE para la intervención en la resolución de conflictos que no tengan necesariamente que consistir en usos y costumbres cooperativos.

d) Se concluía en la necesidad de la gratuidad del servicio arbitral, por lo menos en lo que a los honorarios de los árbitros se refiere.

e) Se defendió la necesidad de creación, dentro del propio CSCE, de una Institución que, sin personalidad jurídica propia y con el mero carácter instrumental, realizase las funciones arbitrales y conciliadoras: nacía el Servicio Vasco de Arbitraje Cooperativo.

Siendo el CSCE consciente de la facultad que le atribuía el artículo 145.2.f) de la LCE, deseaba facilitar a las cooperativas, a sus organizaciones representativas, y a sus socios, un servicio de arbitraje ágil, práctico y eficaz que con su actividad cotidiana contribuyera a la implantación de una «cultura arbitral» en el ámbito cooperativo vasco.

De esta forma, el 20 de abril de 1998, el Pleno del CSCE aprobaba el Reglamento de Arbitraje Cooperativo (en delante RAC) que fue publicado en el Boletín Oficial del País Vasco el 11 de junio del mismo año.

Pero la última de las reformas estaría todavía por llegar.

\section{E) El Reglamento de resolución de conflictos del Consejo Superior de Cooperativas de Euskadi: Bitartu}

El pasado 21 de septiembre de 2004, fue publicado en el Boletín Oficial del País Vasco, el nuevo «Reglamento sobre procedimientos de resolución de conflictos en las cooperativas vascas». Este Reglamento fue aprobado por el CSCE en su sesión plenaria del pasado día 15 de 
julio, entró en vigor el día 22 de septiembre y tuvo su origen, en principio, en la necesidad de adaptar el anterior Reglamento a la nueva Ley 60/2003, 23 de diciembre, de Arbitraje. Aprovechando dicha necesidad, se entendió conveniente introducir aquellos cambios que se veían necesarios por la experiencia acumulada durante los años de prestación del servicio.

Sí podemos decir que con este nuevo Reglamento se viene a culminar un largo camino emprendido hace más de quince años, creándose definitivamente Bitartu como el Servicio Vasco de Resolución Extrajudicial de Conflictos en Cooperativas. Bitartu nace con la vocación de ir más allá de la mera conciliación y arbitraje, abarcando también los procesos de mediación y posibilitando un papel más activo al conciliador, en la búsqueda de una solución al conflicto.

Este Servicio Vasco de Resolución Extrajudicial de Conflictos en Cooperativas, siguiendo lo establecido en los antecedentes que hemos ido viendo, va a conocer por tanto de las cuestiones litigiosas, las que se susciten entre las cooperativas, entre éstas o sus diferentes órganos sociales y sus socios, y en el seno de las mismas entre sus socios.

Evidentemente, y tal como también indicaba el reglamento anterior, el conocimiento de las cuestiones litigiosas, las que se susciten entre los socios cooperativistas, se limita a las que se deriven de la actividad cooperativa, excluyéndose cualesquiera otras que pudieran constituir relaciones particulares entre los mismos.

Además, Bitartu debe fomentar las medidas para la prevención de los conflictos en las cooperativas vascas, así como atender a las necesidades de formación en la resolución de los mismos, que puedan desprenderse del propio sector cooperativo, función ésta novedosa respecto a las que con anterioridad venía desempeñando el Servicio Vasco de Arbitraje Cooperativo.

La sede de Bitartu se encuentra en el propio Consejo Superior de Cooperativas de Euskadi, siendo de aplicación a estos efectos todo lo regulado respecto a la misma en el Reglamento de funcionamiento de esta entidad.

La estructura de Bitartu es, a efectos operativos, la siguiente: Presidente, Secretario, árbitros, conciliadores y mediadores.

Pero cuáles son las principales novedades que ha introducido el Reglamento: 
En relación con el arbitraje, estas novedades son —entre otras-, la resolución del arbitraje siempre en derecho, salvo que las partes acuerden lo contrario; los plazos del nuevo Reglamento se computarán por días naturales; se introducen una serie de supuestos temporales de suspensión del procedimiento arbitral; la gratuidad de los procedimientos hasta el importe que acuerde anualmente el Pleno del Consejo (importe que será publicado en el Boletín Oficial del País Vasco); y la encomienda a los árbitros de la resolución de forma motivada en el laudo de las posibles denuncias del convenio arbitral que puedan efectuar las partes así como de las excepciones que puedan plantearse en el procedimiento.

Continuando con las novedades, y a diferencia de lo previsto en el reglamento anterior, los escritos de demanda y contestación no se formulan de forma simultánea, sino que en primer lugar es el demandante el que debe formular su demanda y proposición de prueba, alegando los hechos en que se funda, la naturaleza y las circunstancias de la controversia, así como las pretensiones. Posteriormente los árbitros remiten todo ello a la parte demandada para que presente su escrito de contestación y proposición de prueba, dándose traslado de los mismos a la parte demandante.

Aparece, igualmente como novedad respecto al reglamento anterior, la posibilidad de que la parte demandada, si lo estima conveniente, pueda reconvenir en su escrito de contestación, formulando contra el demandante otras pretensiones.

Se posibilita que, si las partes llegan a un acuerdo que pone fin total o parcialmente a la controversia durante las actuaciones arbitrales, los árbitros den por terminadas las mismas con respecto a los puntos acordados y, si ambas partes así lo solicitan y los árbitros no aprecian motivos para oponerse, se haga constar este acuerdo en forma de laudo en los términos convenidos por las partes. Este laudo tiene la misma eficacia que cualquier otro dictado sobre el fondo de la controversia.

Se sigue exigiendo que el laudo conste por escrito, indicándose que así se entiende cuando de su contenido y firmas, quede constancia y sean accesibles para su ulterior consulta, en soporté eléctrico, óptico o de otro tipo.

Y por último, se elimina la necesidad de protocolizar notarialmente el laudo, superando así la injustificada laguna habida sobre esta 
cuestión, y en lo que al arbitraje cooperativo se refiere, en la Ley de arbitraje de 1988.

Frente a una institución, como es la conciliación, que no ha variado demasiado, como venimos reiterando la principal novedad en el Reglamento es la previsión de la mediación como una fórmula de resolución de las cuestiones litigiosas en las cooperativas vascas.

\section{F) A modo de conclusión}

En todo caso, es inevitable preguntarse sobre el balance habido hasta la entrada en vigor de este nuevo Reglamento. Pues bien, desde la creación del Servicio Vasco de Arbitraje Cooperativo hemos tramitado cerca de cien expedientes, en los que, como es lógico, nos hemos encontrado con las situaciones más dispares, si bien destacan las impugnaciones de acuerdos del Consejo Rector y de la Asamblea General, aquellas que afectan a procedimientos sancionadores, así como a la cuota de liquidación del socio que causa baja en la cooperativa.

Desde el CSCE no podemos más que congratularnos de la respuesta que estamos teniendo en las cooperativas vascas, siendo cada vez más las cooperativas que incorporan la cláusula de sometimiento obligatorio (de sus conflictos) al arbitraje del CSCE (a partir de ahora BITARTU) en sus Estatutos Sociales.

El CSCE ha apostado decididamente por la intervención de los conflictos en las cooperativas vascas en forma de propuesta con un procedimiento de cara a su resolución. Y lo hace mediante tres instrumentos:

a) Mediante el arbitraje, las partes se someten a un procedimiento reglado y confían a BITARTU la designación de un árbitro que adoptará una decisión vinculante para ambas, aplicando el derecho o la equidad, y poniendo así fin a la controversia.

b) La conciliación es un mecanismo no adversarial para la resolución de la controversia mediante el cual se persigue llegar a un acuerdo en una comparecencia ante BITARTU, quien podrá incluso proponer el propio acuerdo.

c) La mediación es un sistema de negociación asistida, mediante el cual las partes involucradas en un conflicto intentan resolverlo por sí mismas con la ayuda de BITARTU que actúa como favorecedor y conductor de la comunicación. 
Pero, como hemos apuntado, el CSCE no se queda tan sólo en la oferta de los procedimientos de resolución de los conflictos sino que ha emprendido una decidida política de fomentar las medidas para la prevención de los mismos en las cooperativas vascas, así como para atender a las necesidades de formación que se deriven del cooperativismo vasco en relación con esta materia.

Serán las cooperativas y el tiempo los que nos evalúen. 